\title{
Uterine Arteriovenous Malformation-A Rare Cause of Abnormal Uterine Bleeding
}

\author{
SHAMSUN NAHAR BEGUM ${ }^{1}$, SHRODDHA NIVEDITA PAUL ${ }^{2}$, FONINDRA NATH PAUL ${ }^{3}$, \\ MUNA SHALIMA JAHAN ${ }^{4}$, PARUL AKHTER ${ }^{5}$,
}

\begin{abstract}
:
Uterine arteriovenous malformation (AVM) is a rare condition with fewer than 100 cases reported in the literature ${ }^{1}$. Despite being rare, it is a life threatening condition. In most cases, it is diagnosed during a severe and acute hemorrhagic event. It has a diverse symptomatology. Clinical presentation varies from no symptom to various degree of menorrhagia with massive life threatening vaginal bleeding. Clinical suspicion is essential for a prompt diagnosis and treatment. This case report describes a 24year old woman who presented with recurrent episodes of severe vaginal bleeding for the last 3 years. Initial episode was after a curettege for incomplete abortion 3years back. Trans-abdominal and transvaginal Doppler ultrasound of the pelvis showed presence of numerous tortuous and engorged vessels throughout the myometrium and both adnexal regions. Bilateral uterine and ovarian artery ligation was performed with significant improvement of patient's symptom.
\end{abstract}

Key words: Abnormal uterine bleeding (AUB), uterine arteriovenous malformation, bilateral uterine and ovarian artery ligation.

\section{Introduction:}

Arteriovenous malformation (AVM) of uterus is a rare cause of uterine bleeding ${ }^{1,2}$. It is a potentially life threatening condition as patients may present with profuse bleeding 3,4 . The lesion has been variably described as crisoid aneurysm, arterio-venous fistula, arterio-venous aneurysm, pulsating angioma or cavernous angioma ${ }^{5}$. Colour Doppler ultrasound provides a noninvasive method for initial diagnosis of this rare condition and confirmation can be made by Digital subtraction angiography ${ }^{3,6}$. Contrast computed tomography (CT) and magnetic resonance imaging (MRI) can detect the entity easily and therefore now a day's even small AVMS can be detected. 3, 6, 7. Conservative management as bilateral uterine artery ligation may be a preferable method of treatment where uterine artery embolisation is not available in order to avoid hysterectomy in patients of child bearing age ${ }^{7}$.

This case report highlights an experience with a patient having this rare gynecological condition in a tertiary hospital of Bangladesh.

\section{Case Report:}

Mrs. F, 24 year old, multipara was admitted at our facility with recurrent episodes of heavy vaginal bleeding for the last 3 years following evacuation and curettage for spontaneous abortion. She had regular cycle with average flow and duration before curettage. Her only child was delivered vaginally 5 years back.

She was treated with cyclical progesterone, combined oral pill and LNGUS for variable period of time with little improvement. This time her bleeding was heavy and life threatening. And during admission she was pale, pulse 100 beats/min. and BP was $80 / 50 \mathrm{~mm}$ of $\mathrm{Hg}$. Vaginal examination revealed bulky uterus, soft in consistency with healthy cervix. Vascular pulsation was felt through both fornices mostly on left side (feeling like bag of worms). Bleeding was moderate in amount.

Routine Gray scale ultrasound revealed inhomogeneous myometrium with numerous engorged tortuous vessels in both adnexal regions. Colour Doppler ultrasonography also revealed presence of

1. Professor and Head, Department of Obstetrics and Gynecology, SSMC Mitford Hospital, Dhaka

2. Junior Consultant, Department of Obstetrics and Gynecology, SSMC Mitford Hospital, Dhaka

3. Radiologist, Dhaka Medical College Hospital

4. Associate Professor, Department of Obstetrics and Gynecology, SSMC Mitford Hospital, Dhaka

5. Assistant Professor, Department of Obstetrics and Gynecology, SSMC Mitford Hospital, Dhaka 

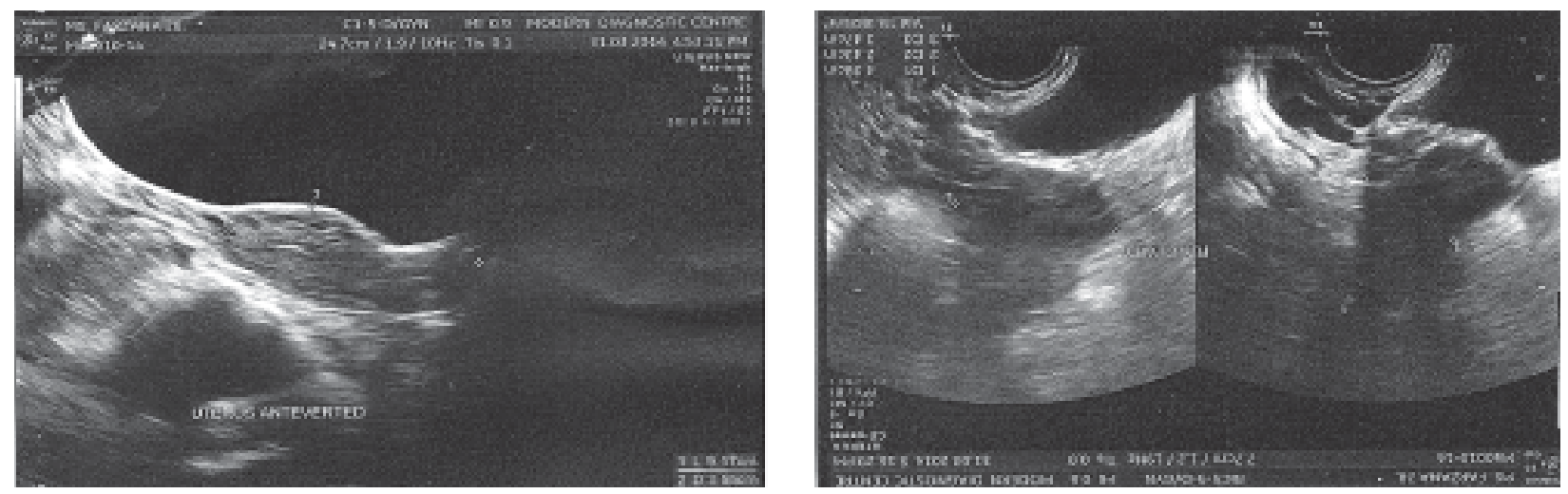

Fig.-1: Gray scale images of the arterovenous malformation with prominent cystic spaces within the myometrium and adnexal region.
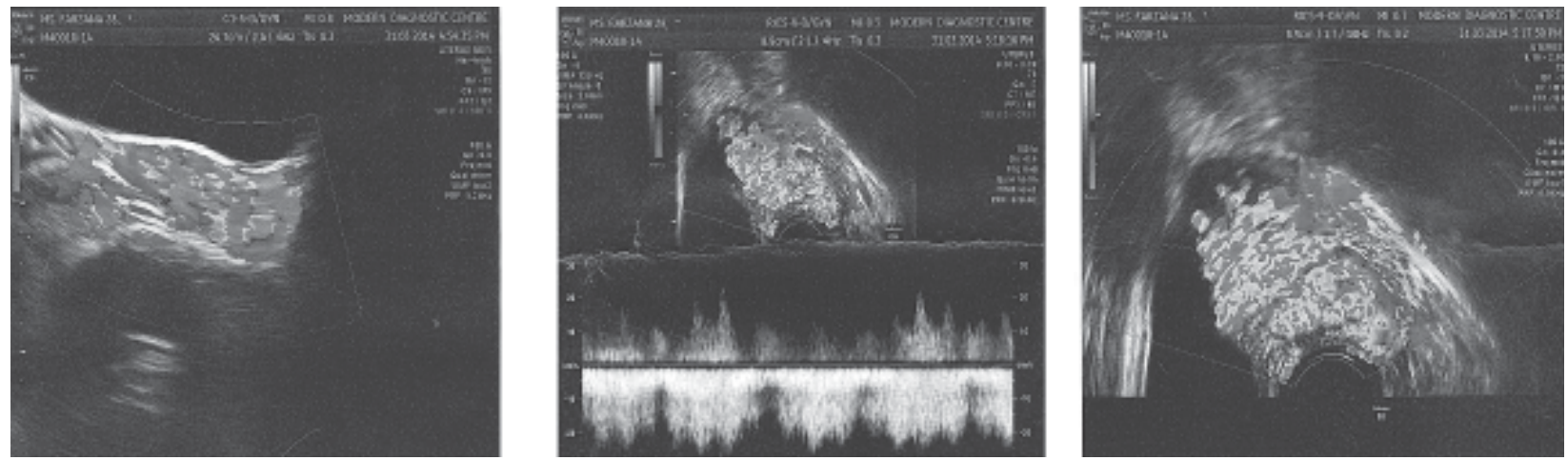

Fig.-2: Colour Doppler images of arteriovenous malformation showing high arterial and venous flow through myometriam.
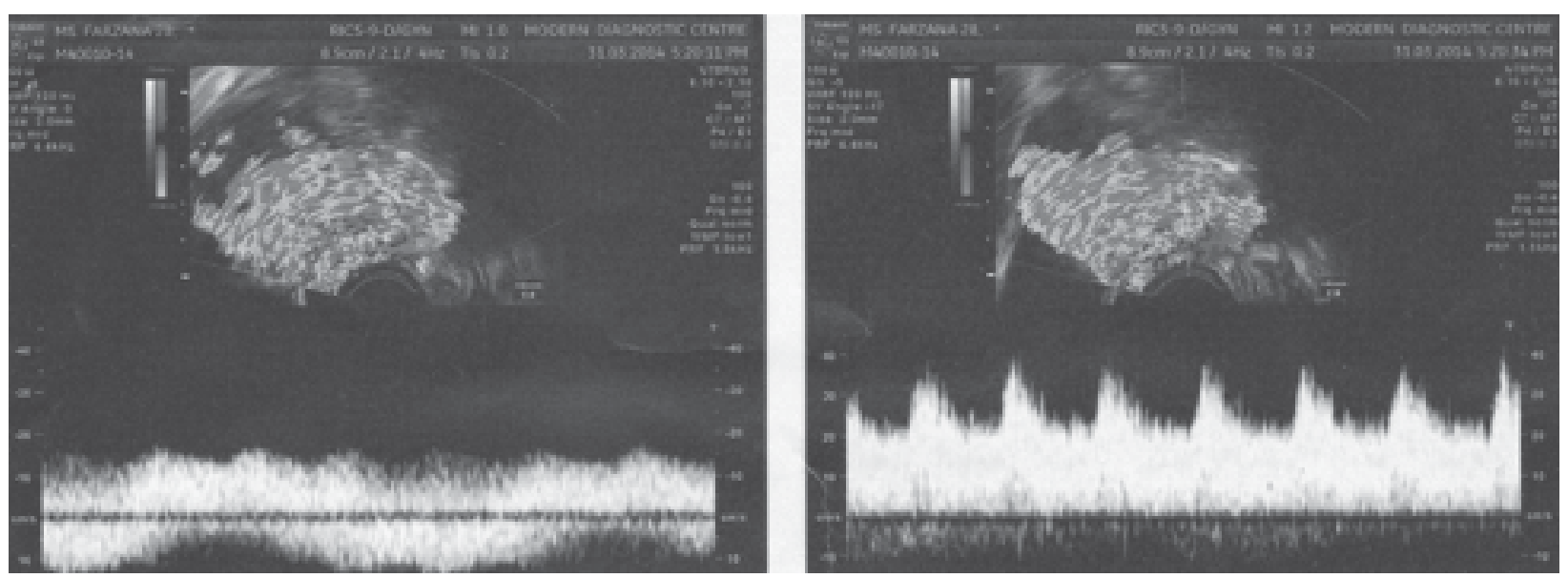

Fig.-3: Pulsed Doppler images showing the broad spectral waveform with continuous flow throughout systole and diastole. 
numerous tortuous and engorged vessels throughout the myometrium and both adnexal regions. These vessels showed mainly high venous and some arterial flow. Hb\% $7.0 \mathrm{gm} / \mathrm{dl}$, Serum beta hCG was normal $(<2 \mathrm{miu} / \mathrm{ml})$.

She was treated by 3 units of packed cell, tranexamic acid and high dose oral pill but her bleeding continued. As uterine artery embolization is not available in our institution so decision was taken for bilateral uterine and ovarian arteries ligation. During laparotomy uterus was found 10-12 weeks pregnancy size, soft with engorged, pulsatile vessels over the whole of uterus and fornices. Vesicouterine pouch was opened after giving a incision over the peritoneum and ureter was identified. Uterine artery was ligated lateral to the ureter on both side and ovarian artery was ligated at the cornual end. Interestingly it was found that immediately after ligation of vessels uterus became firmer with reduced vascular pulsation. She was followed up for consecutive six months having regular menstrual cycle with average flow and duration. But her last ultrasonogram revealed increased vascularity, which may reflect the inherent vascular anomaly.

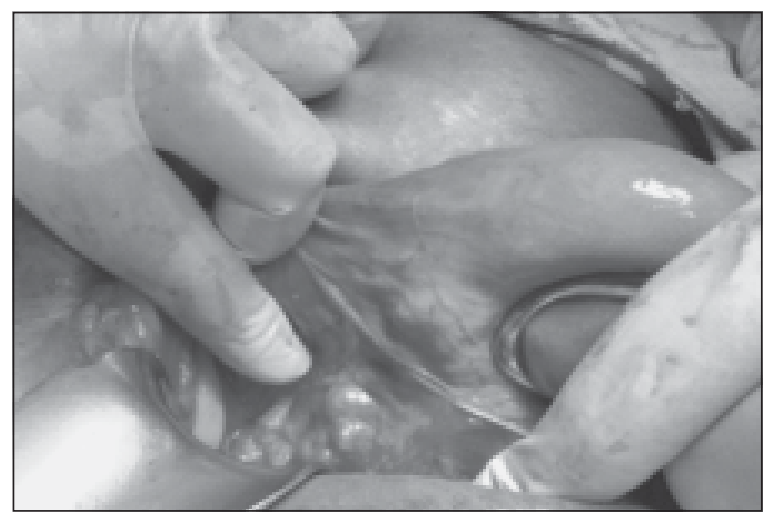

Fig: Peroperative finding of Uterine AVM

\section{Discussion:}

Uterine vascular abnormalities are rare gynecological entities $^{1}$. The first case of arterio-venous malformation (AVM) was reported in 1926 by Dubreuil and Loubat ${ }^{4}$. It is a potentially life threatening disorder in which patients present with profuse vaginal bleeding which might cause hemodynamic instability ${ }^{5}$. Thus, it is an important differential diagnosis in women of reproductive age with unexplained vaginal bleeding 4 and in post-menopausal women when anechoic structures are identified by Ultrasonography ${ }^{2,5}$.
There is abnormal communication between an artery and a vein ${ }^{1}$. Histological examinations reveal a localized proliferation of both arterial and venous vessels with interconnecting fistulae ${ }^{1}$. In many cases, distinction between artery and vein becomes blurred due to secondary intimal thickening of vein as a result of increased intraluminal pressure ${ }^{1,4,8-10}$.

AVMS can be congenital or acquired and have been reported in women aged 18-72 years ${ }^{1,2}$. Most congenital uterine AVMS are isolated anomalies but can occur in association with AVM at other sites ${ }^{2}$. Acquired causes of uterine AVM occur following previous uterine surgery like curettage, caesarean section or hysterectomy, pelvic trauma, previous pregnancy, gestational trophoblastic diseases, exposure to diethyl stilbesterol, endometriosis, fibromyoma and endometrial or cervical cancers ${ }^{3}$.

Pregnancy appears to have an important role in the pathogenesis of uterine arteriovenous malformations ${ }^{5}$, 8 . It is postulated that these malformations may arise when venous sinuses become incorporated in scars within the myometrium. This patient had a past history of curettage, suggesting that this malformations could be due to acquired cause.

Bleeding presumably occurs when the vessels erode or the endometrium becoming exposed in the process $4,5,8$. The pattern of bleeding is usually intermitent and torrential and sometimes significant enough to require multiple blood transfusions ${ }^{2}$. This patient also presented with profuse bleeding which required immediate blood transfusions.

Uterine arteriovenous malformation has been traditionally diagnosed by laparotomy or during histopathology of the uterus after hysterectomy. 2, 4,9 However, color Doppler ultrasonography, a non invasive method can now be used to detect this rare condition. 3, 5, 7 The current gold standard method of diagnosis is digital subtraction pelvic angiography. ${ }^{7}$ This invasive procedure allows confirmation of the diagnosis and also helps to identify the leading "feeder" vessels where embolization may be done as a conservative treatment option ${ }^{9}$.

Gray scale Ultrasonography alone may play a role in diagnosis. It can detect the presence of multiple tubular or "spongi" anechoic or hypoechoic areas within the myometrium. However, other conditions may 
present a similar appearance, such as retained product of conception, hemangioma, gestational trophoblastic disease, multilocular ovarian cysts or hydrosalpinx. , 6,7 Other non invasive procedure for diagnosing AVM is Doppler sonography which, normally reveals a low resistance blood flow with high peak velocities $(136 \mathrm{~cm} / \mathrm{s})$ and evidence of turbulence. There is continuous high blood flow throughout both the systolic and diastolic components of the cardiac cycle. ${ }^{3,6,7}$

Diagnosis of arteriovenous malformation by colour Doppler sonography determined the correct approach to management. It is recommended that a transvaginal scan and colour Doppler assessment should be performed on any woman with moderate to severe abnormal uterine bleeding to exclude this rare but dangerous abnormality. 5, 6 .

Management of uterine AVM depends on hemodynamic status, degree of bleeding, patient's age and desire for future fertility. ${ }^{5,7,9}$ Acute treatment involves stabilizing the patient's hemodynamic status and stopping blood loss. ${ }^{11,12,13}$ Traditionally, hysterectomy was the treatment of choice. Fleming et al reported six cases of AVM where total abdominal hysterectomy was performed for life threatening haemorrhage ${ }^{4}$. Wiebe and Switzer reported seven cases of AVM's diagnosed by colour Doppler and subsequently managed the cases conservatively with spontaneous resolution ${ }^{13,14}$.

Moreover, oral contraception as well as intramuscular and subsequent oral methylergonovine maleate, Danazol have been shown to be associate with regression of lesions based on ultrasonography. 7,12,14

Uterine AVM have been treated successfully by intra arterial embolization with particulate matter like polyvinyl alcohol gel foam, microfibrillar collagen, isobutyl cyanoacrylate and steel coil spring occluders $^{8,1}$

In this case, considering her age, parity and non responsive to medical management, decision was taken for conservative surgery. Following laparotomy bilateral uterine and ovarian artery ligation was done. Pregnancy following conservative medical management of AVM and even after successful embolization although rare but has been reported in literature ${ }^{13,15,16}$.

\section{Conclusion:}

Uterine AVM are not so rare than previously thought. It should be considered as a possibility in cases of refractory uterine bleeding. Colour Doppler sonography is important for proper assessment of the lesion. The size and site of the lesions probably have a major role in deciding whether the patient needs medical or surgical management.

\section{References:}

1. Hilwati $\mathrm{H}$, Ouzreiah $\mathrm{N}$, Uterine Arteriovenous Malformation . Malays J Med Sci. Mar 2013; 20(2):76-80.

2. Hickey M, Fraser I, Clinical implications of Disturbances of uterine vascular morphology and Function. Baillieres Clin Obstet Gynecol. 2000; 14(6); 937-951.

3. Polat P, Suma S, Kantarcy M, Alper F, Levent A. Color Doppler Ultrasound in the Evaluation of Uterine Vascular Abnormalities. Radiographics. 2002; 22: 47-53.

4. Fleming $\mathrm{H}$, Ostor $\mathrm{A}$, Pickle $\mathrm{H}$, Fortune $\mathrm{D}$, Arterio venous malformation of the uterus Obstet Gynaecol 1989, 73 (2): 204-213.

5. Grivell R, Reid K, Mellor A: Uterine Arterio Venous Malformation; A review of current literature, Obstet Gynaecol survey 2005; 60(11): 761-767.

6. Huang M, Muradali D, Thrunston W, Burns P, Wilson S. Uterine arteriovenous malformations: Gray scale and Doppler US features with MR imaging correlation. Radiology 1998; 206(1): 115123.

7. Timmerman D, Bosch Tvd, Peeraer K, vascular malformation in the uterus: Ultrasonographic Diagnosis and conservative management .Euro J obstet Gynaecol Repord Biol.2000;92:171178.

8. Ichikawa Y, Nakauchi T, Sato T, Oki A, Tsunoda $\mathrm{H}$, Yoshikawa $\mathrm{H}$. Ultrasound diagnosis of uterine Arteriovenous fistula associated with placental site trophoblastic tamour. Ultrasound obstet Gyneecol 2003; 21(6): 606-608.

9. Delotte J, Chevallier P, Benoit B, Castillon J, Bongain A, Pregnancy after Embolisation. Therapy for uterine Arteriovenous Malformation. Fertility and sterility 2006 Jan; 85(1) 228e, 1-6. 
10. S P Ho, C L Ong, B S Tan , A case of uterine artery pseudoneurysm. Singapore Med J, 2002;43:202-4.

11. Elia G, Counsell C, Singer S J. Uterine artery malformation as a hidden cause of sever uterine bleeding A case Report. J Repord Med 2001; 46:389.

12. Gold berg Rp, Flynn MK, Pregnancy after medical management of uterine arteriovenous malformation. A case report. J Reprod Medicine 2000; 45:961-3

14. Poppe W. Van Assche FA. Wilms et al pregnancy after transcatheter embolization of uterine arterivenous malformation. Am J. Obstet Gynaecol 1987; 156: 1179-80.

15. Takeuchik, Yamada T, Iwasa M, Maruo T. Successful medical treatment of AVM with Danazol after failed embolization of uterine artriovenous malformation. Obstet Gynaecol. 2003 Oct;102(4):843-844.

16. Yokomine $D$, Yoshinaga $M$, Baba $Y$, Matsuo $T$, Iguro Y, Nakajo M, Douchi T. Successful management of uterine arteriovenous malformation by ligation of feeding artery after unsuccessful uterine artery embolization. $\mathrm{J}$ Obstet Gynaecol Res.2009 Feb;35(1):183-188. 